\title{
Price-Cap Regulation and the Incentive to Cooperate in Research
}

Mark W. Frank

Sam Houston State University $\bullet$ Huntsville, Texas

\begin{abstract}
This paper considers the impact of price-cap regulation on R\&D and the incentive of firms to form research joint ventures. Using a symmetric two-stage duopoly model of cost-reducing R\&D with multiple forms of research cooperation, we find that $R \& D$ is greatest when firms fully cooperate in research and share all research knowledge. Price-cap regulation, however, appears to have a small but negative effect on $R \& D$, leading to lower total welfare.
\end{abstract}

\section{Introduction}

During the 1990s the telecommunications industry, along with other traditionally regulated industries, replaced rate-of-return forms of regulation with pricecap and other incentive-based types of regulation.' Before the divestiture of AT\&T in 1984, for example, all 50 states employed rate-of-return regulation to regulate intrastate telecommunication operations. Following the divestiture, however, several states began experimenting with alternative forms of incentive-based regulations (e.g. earnings sharing regulation, rate case moratoria, and price-cap regulation). ${ }^{2}$ By 1996, price-cap regulation had emerged as the most common form of these new regulations. By the time of the new millennium, only twelve states retained the use of rate-of-return regulation, while thirty-five utilized price-cap regulation (see $\mathrm{Ai}$ and Sappington, 2002).

The rise of price-cap regulation can be attributed to its potential of providing stronger incentives for innovation than traditional rate-of-return regulation (see Vogelsang, 2002; Clemenz, 1991; Cabral and Riordan, 1989). ${ }^{3}$ Empirical support for this view has gained considerable ground in recent years. Studies by Ai and Sappington (2002), Prieger (2002; 2001), and Resende (2000) have all found price-caps to be associated with greater innovation and greater productive efficiency, while Uri (2001a) and Lehman and Weisman (2000) have found qualified support.

The potential of price-cap regulation to encourage greater innovation has special importance in industries such as telecommunications, where innovations play a critical role in the industry's growth. Uri (2001b), for example, finds that productivity in telecommunications increased nearly $5 \%$ per year in the $1990 \mathrm{~s}$, with much of this growth primarily due to the development of new production technolo- 
gies. The practice of developing these innovations, however, has increasingly involved firms cooperating with other firms. Duysters and Hagedoorn (2000) find that joint research partnerships in telecommunications during the 1989 to 1996 period were up $317 \%$ over the 1980 to 1988 period. ${ }^{4}$ This emerging practice of regulated firms increasing R\&D through R\&D cooperation with other firms, however, remains largely ignored in the theoretical and empirical literatures.

The purpose of this paper is to explore the impact of price-cap regulation in an environment where firms may choose to cooperate in the development of research. Our analysis relies on a symmetric two-stage duopoly model to compare R\&D and output levels both with and without price-cap regulation. In the initial stage, firms must choose to either compete in the production of $R \& D$, form a research joint venture by cooperating in the production of $R \& D$, or cooperate in the production of $R \& D$ and fully share all cost-reducing research information. Table 1 presents a summary description of these three research scenarios. In the second stage of our model, firms compete in the output market. ${ }^{5}$ The results are then compared based on the substitutability of the firm's products, the presence and efficacy of price-cap regulation and the degree to which new knowledge can spillover to rival firms. A spillover occurs, for example, when a firm's privately created knowledge becomes publicly available and the firm lacks any legal mechanism to enforce excludability. ${ }^{6}$

Table 1

Research Scenarios

\section{Research Scenario R\&D Production}

Noncooperative

Research (N)

Firms are noncooperative in the production of $R \& D$.

Cooperative

Research (C)

Firms cooperate in the production of R\&D.

Firms cooperate in the production of R\&D.

\section{R\&D Spillovers}

Firms do not fully share cost reducing research information, although some information may become public $(0 \leq \sigma<1)$.

Firms do not fully share cost reducing research information, although some information may become public $(0 \leq \sigma<1)$.

Firms fully share all cost reducing research information $(\sigma=1)$.

Our findings indicate that the intersection between regulatory policies and research cooperation matters. $\mathrm{R} \& \mathrm{D}$ is greatest when firms cooperate in the produc- 
tion of research, fully share all research information, and are unregulated. Production output, however, is greatest when firms cooperate in the production of research, fully share all research information, but are subject to price-cap regulation. With respect to the three research scenarios, research production cooperation coupled with full research information sharing (CS) consistently dominates noncooperative research production $(\mathrm{N})$ and cooperative research production $(\mathrm{C})$. When $\mathrm{R} \& \mathrm{D}$ information has a low rate of spillover to other firms, noncooperative research production dominates cooperative research production. When the information spillover rate is high, however, cooperative research production dominates noncooperative research production.

The following section presents the initial postulations and the subgame-perfect Nash equilibrium outcomes. The final section presents an analysis of the results and suggestions for further research. All proofs are included in the Appendix.

\section{The Model}

Consider an industry of two firms with the linear inverse demand:

$$
P=a-q_{i}-\beta q_{j}, \quad \beta \in(0,1)
$$

where $P$ is market price, $q_{i}$ is output from the $i^{i h}$ firm, $q_{j}$ is output from the $j^{\text {th }}$ firm, and $\beta$ is a substitutability parameter. If $\beta=1$, then $q_{i}$ and $q_{j}$ are perfectly substitutable. If $\beta=0$, then $q_{i}$ and $q_{j}$ are perfectly unsubstitutable (i.e. each firm is a monopoly).

Assume that per unit production cost may be lowered through cost reducing $R \& D$,

$$
c_{i}=c-x_{i}-\sigma x_{j}, \quad \sigma \in(0,1)
$$

where $x_{i}$ is cost reducing R\&D from the $i^{\text {th }}$ firm and $x_{j}$ is cost reducing R\&D from the $j^{\text {th }}$ firm. We assume that $\mathrm{c}>x_{i}+\sigma x_{j}$, since costs cannot be negative. The parameter $\sigma$ represents exogenous $R \& D$ spillovers. If both firms agree to fully share all costreducing research information, then the spillover is internalized, and $\sigma=1$.

In the absence of a research information sharing agreement, some research knowledge may still spillover given the public good nature of knowledge, hence $0 \leq \sigma<1$. Knowledge spillovers may also arise by deliberate disclosures or involuntary leaking, for example. The case of $\sigma=0$ would imply that all cost-reducing research information remains private to the firm. 
Following from d'Aspremont and Jacquemin (1988), De Bondt, Slaets, and Cassiman (1992), and Poyago-Theotoky (1995), it is assumed that the total cost of firm $i$ 's own R\&D reflects the existence of decreasing returns to scale:

$$
\gamma \frac{x_{i}^{2}}{2}
$$

where $\gamma$ is the price of R\&D.

Price-cap regulation (PC) involves the imposition of a binding price ceiling that is periodically adjusted downwards by a preannounced productivity factor. In the literature on PC regulation, it is common to assume that the regulated price is initially set equal to the firm's per unit production costs, thus enabling the firm to make normal profits (see Heyes and Liston-Heyes, 1998; Clemenz, 1991; Carbral and Riordan, 1989). This price-cap is then periodically adjusted downwards by some factor $X$ (often referred to as the $R P I-X$ factor, where $R P I$ is the retail price index). This adjustment lowers the price-cap to account for changes in projected industry-wide technological improvement. ${ }^{7}$ Firms can make greater than normal profits if they produce cost-reducing innovations in excess of $X$. If firms produce innovations amounting to less than $X$, however, they may request a rate hearing. The result of this rate hearing will be that the regulator adjusts the price-cap so that the firm is again making normal profits. ${ }^{8}$

It is assumed that the firm never chooses a price below the PC (hence, the $\mathrm{PC}$ is binding). The regulator initially sets the price-cap equal to the firm's per unit production costs. This cap is subsequently adjusted downwards by $X$ :

$$
\bar{P}=c-X .
$$

The objective of the regulator is to anticipate future cost-reducing innovations by the firm, meaning $\bar{P}=c-x_{i}-\sigma x_{j}$. The firm will be able to gain financially if actual cost reductions $\left(x_{i}+\sigma x_{j}\right)$ are greater than the adjustment factor $(X)$. If $X>x_{i}+\sigma x_{j}$ , however, the firm requests a rate hearing and forces the regulator to set $X=x_{i}+$ $\sigma x_{j}$.

From (1), the inverse demand is $P=a-q_{i}-\beta q_{j}$. Hence, the per unit regulatory objective is:

$$
\left(a-q_{i}-\beta q_{j}\right)-c+x_{i}+\sigma x_{j}=0
$$


The problem for the $\mathrm{PC}$ regulated firm is then to maximize profits subject to the regulatory constraint:

$$
L=\left(a-q_{i}-\beta q_{j}-c+x+\sigma x_{j}\right) q_{i}-\gamma \frac{x_{i}^{2}}{2}-\lambda\left(a-q_{i}-\beta q_{j}-c+x_{i}+\sigma x_{j}\right),
$$

where $0 \leq \lambda \leq 1$, and $\lambda$ reflects the efficacy of regulation. This is the second stage payoff function for the $i^{\text {th }}$ firm. As $\lambda$ approaches one, regulation converges to the regulator's objective (5). As $\lambda$ falls towards zero, regulation diverges from the regulator's objective ( $X$ falls increasingly further below the actual amount of cost-reducing innovation, $\left.x_{i}+\sigma x_{j}\right)$.

Proposition 1: If $\sigma>\frac{\beta}{2}$, then $x_{i}^{C S}>x_{i}^{C}>x_{i}^{N}, q_{i}^{C S}>q_{i}^{N}$, and $W_{i}^{C S}>W_{i}^{C}$ $>W_{i}^{N}$. If $\sigma<\frac{\beta}{2}$, however, $x_{i}^{C S}>x_{i}^{N}>x_{i}^{C}, q_{i}^{C S}>q_{i}^{N}>q_{i}^{C}$, and $W_{i}^{C S}>$ $W_{i}^{N}>W_{i}^{C}$. (Proof provided in the Appendix.)

Proposition 1 tells us that $\mathrm{R} \& \mathrm{D}$ is greatest under research cooperation coupled with full sharing of all cost reducing R\&D information $\left(x_{i}^{C S}\right)$. When spillovers of research information are greater than 0.5 and product substitutability is sufficiently low, noncooperative research production $\left(x_{i}^{M}\right)$ is inferior to cooperative research production, ceteris paribus. This relationship is plotted in Figure 1. The shaded area represents values of $\sigma$ and $\beta$ that result in $x_{i}^{N}$ being greater than $x_{i}^{C}$.

This relationship between $x_{i}^{N}$ and $x_{i}^{C}$ occurs because noncooperative research suffers from an appropriability problem; when research information becomes public at a high rate, and rival products are relatively unsubstitutable (the non-shaded area of Figure 1), the firm finds it profit maximizing to reduce their own production of $R \& D$ and free ride off the research efforts of the rival firm. In this case, the firm can overcome this appropriability problem by agreeing to cooperate in the production of R\&D (hence, $x_{i}^{C}>x_{i}^{M}$ ).

Production output and total welfare (the "first-best" standard) follow similarly. If $\sigma>0.5 \beta$, then $q_{i}^{C S}>q_{i}^{C}>q_{i}^{N}$ and $W_{i}^{C S}>W_{i}^{C}>W_{i}^{N}$. If $\sigma<0.5 \beta$, however, $q_{i}^{C S}>q_{i}^{N}>q_{i}^{C}$ and $W_{i}^{C S}>W_{i}^{N}>W_{i}^{C}$. That is, cooperative research production coupled with full information sharing dominates the noncooperative and cooperative research production. The noncooperative research scenario outperforms the cooperative research scenario, so long as information spillovers are less than 0.5 and 
product substitutability is sufficiently high. Otherwise, the appropriability problem causes noncooperative research production to underperform cooperative research production.

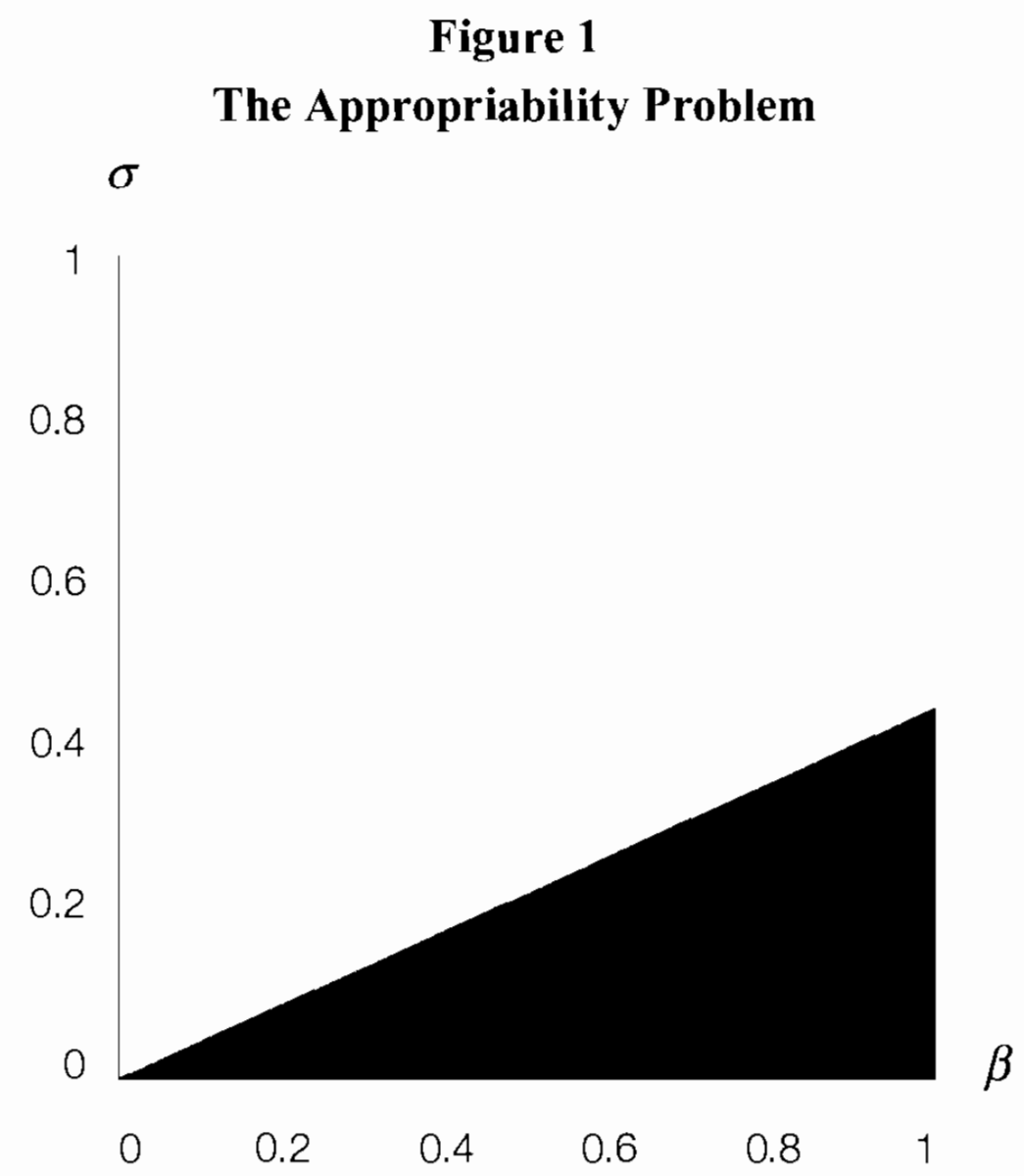

Note: In the shaded area, $x_{i}^{N}>x_{i}^{C}$; in the non-shaded area $x_{i}^{N}<x_{i}^{C}$.

Proposition 2: $R \& D$ and total welfare from each of the three research scenarios are decreasing functions of the $P C$ regulatory parameter, $\lambda$. Production output, however, is an increasing function of the PC regulatory parameter. (Proof provided in the Appendix.)

As the regulatory parameter approaches unity, $\mathrm{R} \& \mathrm{D}$ falls, ceteris paribus. Whenever $\lambda<l$, this implies that the regulator is not able to fully enforce its regulatory objective (5). This would occur when the price-cap is not lowered by the full amount of the firm's cost-reducing $\mathrm{R} \& \mathrm{D}\left(x_{i}+\alpha_{j}\right)$, thus enabling the firm to earn greater than normal profits. When the enforcement of $\mathrm{PC}$ regulation improves (as $\lambda \rightarrow 1$ ), the firm receives less of the benefits from cost-reducing innovation. As a result, $R \& D$ decreases.

Production output under $\mathrm{PC}$ regulation, by contrast, is an increasing function of the regulatory parameter in each of the three research scenarios. As $\lambda \rightarrow 1$, the 
profit maximizing firm is induced to increase production output. This effect has important welfare implications. Better enforcement of $\mathrm{PC}$ regulation forces the firm to transfer the benefits from cost-reducing innovations to consumers in the form of increased output (recall that if $\lambda=1$, then $X=x_{i}+\sigma x_{j}$ ). Consumer surplus, therefore, is increasing in $\lambda$.

What is good for consumers is not, in the case of PC regulation, good for producers. Total profit for the firm under each of the three research scenarios decreases as $\lambda \rightarrow 1$. Lax regulation means the firm can gain greater profits because actual cost-reducing innovations $\left(x_{i}+\sigma_{j}\right)$ are greater than the regulatory productivity-adjustment factor $(X)$. The impact of regulation on total profit within each of the three research scenarios, however, is greater that than the impact on consumer surplus. Hence, as $\lambda$ approaches unity, total welfare decreases.

\section{Conclusion}

This article has considered the impact of price-cap regulation on the incentive to cooperate in R\&D. Our findings are based on a symmetric two-stage duopoly framework in which the firms choose to either compete in the production of R\&D, cooperate in $R \& D$ production, or cooperate in $R \& D$ production and share all research information. The findings have relevance to industries such as telecommunications, where price-cap regulation occurs alongside the increasing use of inter-firm research partnerships.

Figure 2 presents a graphical summary of the $R \& D$ and production output rankings. ${ }^{10}$ The first column of the graphs plots $\mathrm{R} \& \mathrm{D}\left(x_{i}\right)$ on the vertical axes, while the second column plots production output $\left(q_{i}\right)$. Each row presents variations of a different parameter $(\sigma, \beta$, and $\lambda$, respectively), while keeping the remaining two parameters constant at 0.5 . Notice that $x_{i}$ and $q_{i}$ are always greatest when firms cooperate in the production of research and fully share research information (CS). Noncooperative research production $(\mathrm{N})$ performs better than cooperative research production (C) in terms of $\mathrm{R} \& \mathrm{D}$ and output only when research spillovers are less than 0.5 and product substitutability is sufficiently high (i.e. when $\sigma<0.5 \beta$ ). Otherwise, noncooperative research production suffers from an appropriability problem and is inferior to cooperative research production.

With respect to price-cap regulation, $R \& D$ is greatest when the firm is unregulated $(\lambda=0)$, though the impact of regulation appears relatively small. This outcome is replicated in each of the three research scenarios. Production output, by contrast, increases as the efficacy of regulation increases $(\lambda \rightarrow 1)$. This outcome is 
again replicated in each of the three research scenarios. Consequently, price-cap regulation presents important tradeoffs between $R \& D$ and production output. Using a first-best total welfare standard, our analysis suggests that the gains from effective enforcement of price-cap regulation do not offset the R\&D losses, at least in the comparative static setting.

\section{Figure 2}

\section{R\&D and Production Output Comparisons}
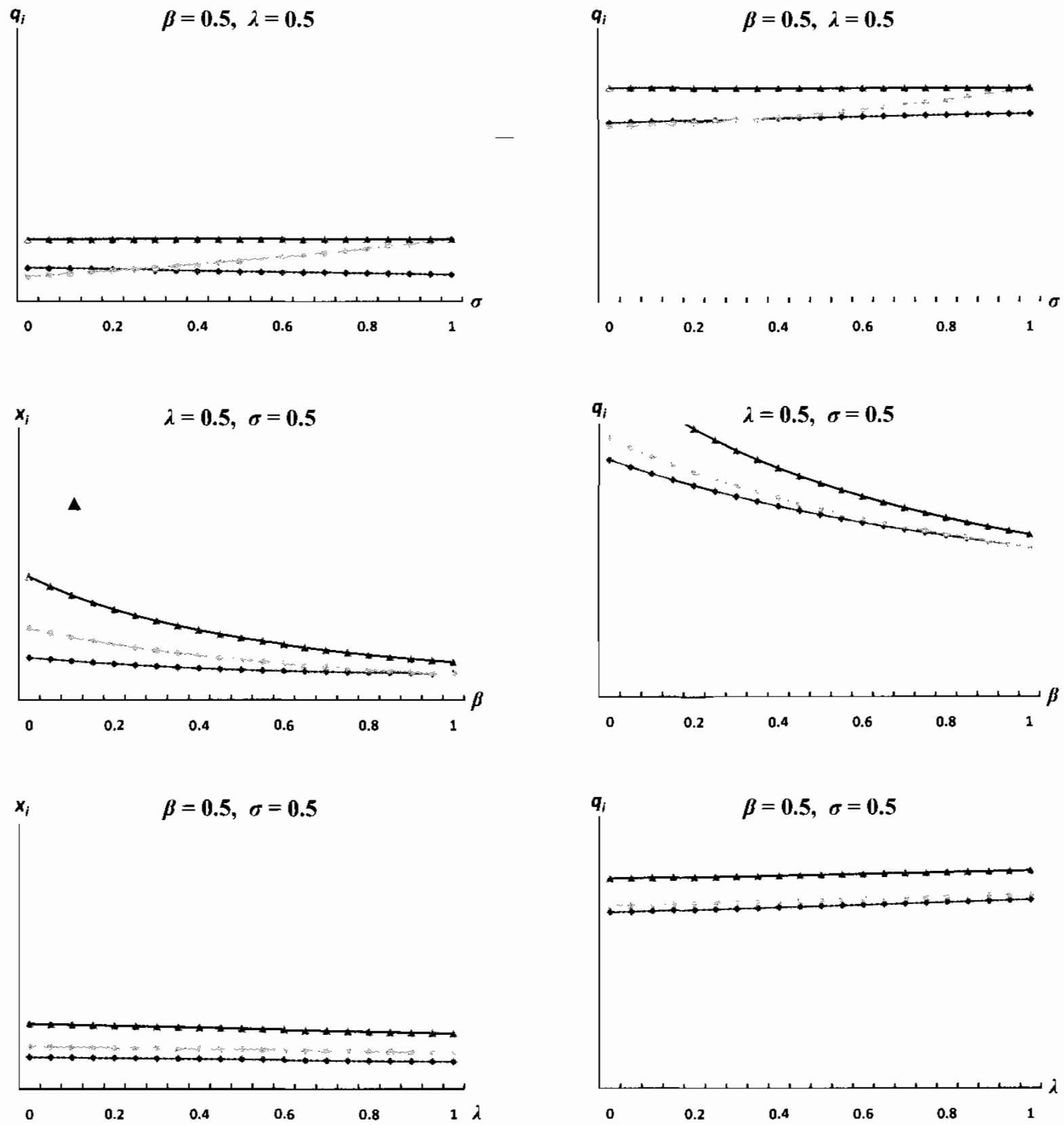

$\rightarrow \mathrm{N}+\mathrm{C} \rightarrow \mathrm{CS}$ 
It remains an open question, however, how robust these findings would be in a more dynamic setting, or what insights empirical testing may provide. Given the ongoing coexistence of price-cap regulation in industries with firms engaging in cooperative research agreements, it is hoped that our findings will prove suggestive for future research.

\section{Acknowledgements}

Thanks to Barry J. Seldon and Donald G. Freeman for helpful comments. Sam Houston State University's Research Enhancement Fund provided financial support for this research project. All errors remain my responsibility.

\section{Appendix}

Proof of Proposition 1: The Nash-Cournot symmetric equilibrium for the second stage is:

$$
q_{i}=\frac{(a-c-\lambda)(\beta-2)+x_{i}(\beta \sigma-2)+x_{j}(\beta-2 \sigma)}{\beta^{2}-4}
$$

If $q_{i}$ were negative, the firm would not produce. It is therefore assumed that $q_{i}$ is positive. This in turn requires that $a-c-\lambda>0$. The first stage payoff function for the $i^{\text {th }}$ firm is found by substituting (A6), into the second stage profit function (9):

$$
\begin{gathered}
\Pi_{i}=\left[\frac{[a-c-\lambda(\beta+1)](\beta-2)+x_{i}(\beta \sigma-2)+x_{j}(\beta-2 \sigma)}{\left(\beta^{2}-4\right)^{2}}\right]\left\{-\lambda\left(\beta^{2}-4\right)+\right. \\
\left.\left[(a-c+\lambda)(\beta-2)+x_{i}(\beta \sigma-2)+x_{j}(\beta-2 \sigma)\right]\right\}-\gamma \frac{x_{i}^{2}}{2} .
\end{gathered}
$$

Under noncooperative research production, the symmetric profit maximizing level of $\mathrm{R} \& \mathrm{D}\left(x_{i}^{M}\right)$ is found by differentiating (A1) with respect to $x_{i}$ :

$$
x_{i}^{N}=\frac{2(a-c-\lambda-\lambda \beta)(2-\beta \sigma)}{\gamma(2-\beta)(2+\beta)^{2}-2(1+\sigma)(2-\beta \sigma)} .
$$

Substituting $x_{i}^{N}$ into (A1) yields the profit maximizing level of production output for the game: 


$$
q_{i}^{N}=\frac{\gamma\left(4-\beta^{2}\right)(a-c+\lambda)-2 \lambda(1+\sigma)(2-\beta \sigma)}{\gamma(2-\beta)(2+\beta)^{2}-2(1+\sigma)(2-\beta \sigma)}
$$

Substituting $x_{i}^{N}$ and $q_{i}^{N}$ into second stage profits (6), reveals firm $i$ 's total profits for the game:

$$
\Pi_{i}^{N}=\frac{\gamma(-a+c+\lambda+\lambda \beta)^{2}\left[\gamma\left(4-\beta^{2}\right)^{2}-2(2-\beta \sigma)^{2}\right]}{\left[\gamma(2-\beta)(2+\beta)^{2}-2(1+\sigma)(2-\beta \sigma)\right]^{2}} .
$$

With linear inverse demand (1), consumer surplus is $q_{i}^{N}(1+\beta)$. Total welfare is the sum of consumer surplus plus profit:

$$
\begin{aligned}
& W_{i}^{N}=\frac{\gamma(-a+c+\lambda+\beta \lambda)^{2}\left[\gamma\left(\beta^{2}-4\right)^{2}-2(\beta \sigma-2)^{2}\right]}{\left[\gamma(\beta-2)(2+\beta)^{2}-2(1+\sigma)(\beta \sigma-2)\right]^{2}}+ \\
& \frac{(1+\beta)\left[\gamma\left(\beta^{2}-4\right)(a-c+\lambda)+2 \lambda\left(2-2 \sigma+\beta \sigma-\beta \sigma^{2}\right)\right]^{2}}{\left[\gamma(\beta-2)(2+\beta)^{2}-2(1+\sigma)(\beta \sigma-2)\right]^{2}}
\end{aligned}
$$

When firms cooperate in the production of $R \& D$, the profit maximizing symmetric level of $R \& D\left(x_{i}^{C}\right)$ is found by adding both profit functions (A2) together and differentiating with respect to $R \& D$ :

$$
x_{i}^{C}=\frac{2(a-c-\lambda-\lambda \beta)(1+\sigma)}{\gamma(2+\beta)^{2}-2(1+\sigma)^{2}} .
$$

Substituting $x_{i}^{C}$ into (A1) yields the profit maximizing level of production output for the game:

$$
q_{i}^{C}=\frac{\gamma(2+\beta)(a-c+\lambda)-2 \lambda(1+\sigma)^{2}}{\gamma(2+\beta)^{2}-2(1+\sigma)^{2}}
$$

Substituting $x_{i}^{C}$ and $q_{i}^{C}$ into second stage profits (6), reveal firm $i$ 's total profits:

$$
\Pi_{i}^{C}=\frac{\gamma(-a+c+\lambda+\lambda \beta)^{2}}{\gamma(2+\beta)^{2}-2(1+\sigma)^{2}}
$$


With linear inverse demand (1), consumer surplus is $q_{i}^{C}(1+\beta)$. Total welfare is the sum of consumer surplus plus profit:

$$
\begin{gathered}
W_{i}^{C}=\left[\gamma(2+\beta)^{2}-2(1+\sigma)^{2}\right]^{2}\left\{\gamma\left[\gamma(2+\beta)^{2}-2(1+\sigma)^{2}\right]\left(-a+c_{i}+\lambda+\lambda \beta\right)^{2}\right. \\
\left.+(1+\beta)\left[2 \lambda(1+\sigma)^{2}-\gamma(2+\beta)(a-c+\lambda)\right]^{2}\right\} .
\end{gathered}
$$

When firms cooperate in the production of $R \& D$ and fully share all costreducing research information, $\sigma=1$. Consequently,

$$
\begin{gathered}
x_{i}^{C S}=\frac{4(a-c-\lambda-\lambda \beta)}{\gamma(2+\beta)^{2}-8}, q_{i}^{C S}=\frac{\gamma(2+\beta)(a-c+\lambda)-8 \lambda}{\gamma(2+\beta)^{2}-8}, \\
\Pi_{i}^{C S}=\frac{\gamma(-a+c+\lambda+\lambda \beta)^{2}}{\gamma(2+\beta)^{2}-8},
\end{gathered}
$$

and

$$
W_{i}^{C S}=\frac{\gamma\left[\gamma(2+\beta)^{2}-8\right](-a+c+\lambda+\lambda \beta)^{2}+(1+\beta)[\gamma(2+\beta)(a-c+\lambda)-8 \lambda]^{2}}{\left[\gamma(2+\beta)^{2}-8\right]^{2}} .
$$

The second order conditions for each of the three research scenarios $(\mathrm{N}, \mathrm{C}$, and CS) are as follows:

$$
\gamma>\frac{2(1+\sigma)(2-\beta \sigma)}{(2-\beta)(2+\beta)^{2}}, \gamma>\frac{2(1+\sigma)^{2}}{(2+\beta)^{2}}, \text { and } \gamma>\frac{8}{(2+\beta)^{2}}
$$

respectively. Note that each ensures that the dominator is always positive.

Consequently, $x_{i}^{C S}$ is greater than $x_{i}^{C}$ for all $\sigma$ and $\beta$ because

$$
\frac{4(a-c-\lambda-\lambda \beta)}{\gamma(2+\beta)^{2}-8}>\frac{2(a-c-\lambda-\lambda \beta)(1+\sigma)}{\gamma(2+\beta)^{2}-2(1+\sigma)^{2}} .
$$

Likewise, $x_{i}^{C}$ is greater than $x_{i}^{N}$ for all $\sigma$ and $\beta$ because 


$$
\frac{4(a-c-\lambda-\lambda \beta)}{\gamma(2+\beta)^{2}-8}>\frac{2(a-c-\lambda-\lambda \beta)(2-\beta \sigma)}{\gamma(2-\beta)(2+\beta)^{2}-2(1+\sigma)(2-\beta \sigma)},
$$

and $x_{i}^{C}$ is greater than $x_{i}^{N}$ only if $\sigma>0.5 \beta$. For small research spillover rates, $\sigma<$ $0.5 \beta, x_{i}^{C}$ is less than $x_{i}^{N}$. Production output, total profit, and total welfare follow similarly. Q.E.D.

Proposition 2: In each of the three research scenarios, R\&D output under PC regulation is decreasing in $\lambda$. This follows because

$$
x_{i}^{N}=\frac{2(a-c-\lambda-\lambda \beta)(2-\beta \sigma)}{\gamma(2-\beta)(2+\beta)^{2}-2(1+\sigma)(2-\beta \sigma)}, x_{i}^{C}=\frac{2(a-c-\lambda-\lambda \beta)(1+\sigma)}{\gamma(2+\beta)^{2}-2(1+\sigma)^{2}},
$$

and

$$
x_{i}^{C S}=\frac{4(a-c-\lambda-\lambda \beta)}{\gamma(2+\beta)^{2}-8} .
$$

Production output, however, is increasing in $\lambda$. Recall that the second order conditions (defined in Proof of Proposition 1) place a minimum level on $\gamma$. In the noncooperative case $\left(q_{i}^{N}\right)$, this follows because

$$
\frac{2(1+\sigma)(2-\beta \sigma)}{4+\beta^{2}}>\frac{2(1+\sigma)(2-\beta \sigma)}{(2-\beta)(2+\beta)^{2}}
$$

for all relevant values of $\beta$ and $\sigma$. In the case of $q_{i}{ }^{C}$,

$$
\frac{2(1+\sigma)^{2}}{2+\beta}>\frac{2(1+\sigma)^{2}}{(2+\beta)^{2}}
$$

and in the case of $q_{i}^{C S}$,

$$
\frac{8}{2+\beta}>\frac{8}{(2+\beta)^{2}}
$$


The profit maximizing firm will produce a positive amount of R\&D under PC regulation so long as $a-c-\lambda-\beta \lambda>0$. Q.E.D.

\section{End Notes}

1. In general, under price-cap regulation the firm will be free to raise its price at the rate of inflation minus an amount set to expected productivity (for an introduction, see Viscusi, 2005).

2. See Ai and Sappington (2002) for a general overview of these changes.

3. In its performance review of AT\&T, the FCC justified its change to price-cap regulation because rate-of-return regulation offered "little incentive to innovate new and innovative services" (FCC 1992, 5322).

4. Duysters and Hagedoorn also report joint formations of separate research corporations are up $87 \%$ between the two periods, while large company investments in small innovative companies (what they term "minority investments") are up $89 \%$. Their findings are from the MERIT-CATI database on inter-firm partnerships, which is maintained by the University of Maastricht (see also, Hagedoorn and Kranenburg, 2003).

5. The possibility of production cooperation is set aside because anti-trust enforcement of production cooperation is a dissimilar policy instrument from price-cap regulation. Moreover, through government policies such as the National Cooperative Research Act (NCRA), R\&D cooperation is actively encouraged by offering antitrust protection to firms who cooperate in the production of R\&D (see Scott, 1989). The same is not true for production cooperation.

6. For a general discussion of knowledge spillovers, see chapter 14 in Martin, 2001.

7. Bernstein and Sappington (1999) provide an analysis of how this adjustment factor should be set under varying market conditions. Note also that our model drops the $R P I$ aspect of the $X$ factor. This is done merely for simplicity, though it has the benefit of avoiding the occurrence of a rising price-cap, which would occur when $R P I$ becomes greater than $X$.

8. In its regulation of AT\&T, the FCC set this adjustment factor $(X)$ at $3 \%$ per year. The FCC argued that AT\&T had historically achieved $2.5 \%$ productivity growth under rate-of-return regulation, and $0.5 \%$ was added as a Consumer Productivity Dividend (CPD) (FCC 1992, 5323). Similarly, in its regulation of British Telecom, the British government initially set $X$ at 3\% (Beesley and Littlechild 1989). 
9. Laffont and Tirole (2002) argue that imperfections in the administration of pricecap regulation are common. Reasons for this include the practice by regulators of using price averages in the monitoring of price-caps, the unsystematic treatment of new services and phasing out of existing services, the lack of an intertemporal price-cap adjustment, and lack of incentives for service quality (see section 2.3 in chapter 2).

10. Figure 2 is based on the numeric assumption that $a-c=10$, and $\gamma=5$.

\section{References}

Ai, C., \& Sappington, D. E. (2002). The impact of state incentive regulation on the U.S. telecommunications industry. Journal of Regulatory Economics, 22, 13360 .

Beesley, M. E., \& Littlechild, S. C. (1989). The regulation of privatized monopolies in the United Kingdom. RAND Journal of Economics, 20, 454-72.

Bernstein, J. I., \& Sappington, D. E. (1999). Setting the $X$ factor in price cap regulation plans. Journal of Regulatory Economics, 16, 5-25.

Cabral, L. M., \& Riordan, M. H. (1989). Incentives for cost reduction under price cap regulation. Journal of Regulatory Economics, 1, 93-102.

Clemenz, G. (1991). Optimal price cap regulation. The Journal of Industrial Economics 39, 391-408.

De Bondt, R., Slaets, P., \& Cassiman B. (1992). The degree of spillovers and the number of rivals for maximum effective R\&D. International Journal of Industrial Organization, 10, 35-54.

Duysters, G., \& Hagedoorn, J. (2000). A note on organizational modes of strategic technology partnering. Journal of Scientific \& Industrial Research, 58, 640-49.

D'Aspremont, C., \& Jacquemin, A. (1988). Cooperative and noncooperative R\&D in duopoly with spillovers. American Economic Review, 78, 1133-37.

Federal Communications Commission. (1992). Price cap performance review for AT\&T. Notice of inquiry filed in CC Docket 92-134, 7 FCC Red 5322.

Hagedoorn, J., \& Kranenburg, H. (2003). Growth patterns in R\&D partnerships: An exploratory statistical study. International Journal of Industrial Organization, $21,517-31$.

Heyes, A. G., \& Liston-Heyes, C. (1998). Price cap regulation and technical change. Journal of Public Economics, 68, 137-51.

Laffont, J. J., \& Tirole, J. (2002). Competition in Telecommunications. Cambridge, Massachusetts: MIT Press. 
Lehman, D. E., \& Weisman, D. L. (2000). The political economy of price cap regulation. Review of Industrial Organization, 16, 343-56.

Martin, S. (2001). Advanced Industrial Economics, (2nd ed.). New York: WileyBlackwell.

Poyago-Theotoky, J. (1995). Equilibrium and optimal size of a research joint venture in an oligopoly with spillovers. The Journal of Industrial Economics, 63, 209-26.

Prieger, J. E. (200l). Telecommunications regulation and new services: A case study at the state level. Journal of Regulatory Economics, 20, 285-305.

Prieger, J. E. (2002). A model for regulated product innovation and introduction with application to telecommunications. Applied Economics Letters, 9, 625-29.

Resende, M. (2000). Regulatory regimes and efficiency in U.S. local telephony. Oxford Economic Papers, 52, 447-70.

Scott, J. T. (1989). Historical and economic perspectives of the national cooperative research act. In Link, A. N. \& Tassey, G. (Eds.) Cooperative Research and Development: The Industry-University-Government Relationship. Norwell, Massachusetts: Kluwer Academic Publishers.

Uri, N. D. (2001a). Technical efficiency, allocative efficiency, and the implementation of a price cap plan in telecommunications in the United States. Journal of Applied Economics, 4, 163-86.

Uri, N. D. (2001b). Telecommunications in the United States and changing productive efficiency. Journal of Industry, Competition and Trade, 1, 321-335.

Viscusi, W. K. (2005). Economics of Regulation and Antitrust, (4th ed.). New York: The MIT Press.

Vogelsang, I. (2002). Incentive regulation and competition in public utility markets: A 20-year perspective. Journal of Regulatory Economics, 22, 5-27.

\section{Biographical Sketch of Author}

Mark Frank is an Associate Professor of Economics and International Business at Sam Houston State University. He received his Ph.D. from the University of Texas at Dallas. His research interests include telecommunications regulation, the economics of advertising in the liquor industry, and income inequality within the United States. 
